\title{
LXXVI. Results of the repetition of Mr. Potter's experiment of interposing a prism in the path of interfering light
}

\section{Professor G.B. Airy}

To cite this article: Professor G.B. Airy (1833) LXXVI. Results of the repetition of Mr. Potter's experiment of interposing a prism in the path of interfering light, Philosophical Magazine Series 3, 2:12, 451-451, DOI: 10.1080/14786443308648087

To link to this article: http://dx.doi.org/10.1080/14786443308648087

曲 Published online: 01 Jun 2009.

Submit your article to this journal $\pi$

Џll Article views: 3

Q View related articles 5 
Prof. Airy's Repetitions of Mr. Potter's Experiment. $45 \mathrm{l}$

first time that I witnessed the electric spark by magnetic excitation, it was shown to me by Mr. Watkins, in his shop at Charing-cross, some considerable time after it had been shown in London by Mr. Saxton, with a similar apparatus.

LXXVI. Results of the Repetition of Mr. Potter's Experiment of interposing a Prism in the Path of Interfering Light. By Professor AlRY*.

To the Editors of the Philosophical Magazine and Journal.

Gentlemen,

I HAVE lately had several opportunities of repeating, under

favourable circumstances, Mr. Potter's experiment of interposing a prism in the path of interfering light, and am able to assert positively, as an experimental fact, that the gradual displacement and ultimate disappearance of the centre of the fringes take place in the manner which I stated as a consequence of theory; namely, that on receding from the prism, the fringes remain stationary; while their character changes, in such a manner, that the centre of fringes passes gradually and rapidly from the centre of the mixture of lights to its border.

The apparatus which $I$ have used consists of an eye-piece, with a wire fixed in its focus, attached to a support which slides on a bar that is placed in a position parallel to the path of the light after refraction at the prism. By proper adjustment of this bar, the wire may be kept steady upon one of the fringes while the eye-piece is drawn from contact with the prism to the greatest distance at which the fringe is visible. In this manner I have kept one fringe under the wire, with the certainty that, though its colour has altered, it has not deviated half the breadth of a fringe; while the centre of fringes has gradually moved through the space occupied by twelve double fringes.

I have made the experiment with light of various degrees of heterogeneity, and in all cases, as far as I could judge, the displacement of the centre of fringes was the same at the same distance; which is also a result of theory. It is necessary to observe that, when the light is nearly homogeneous, the number of visible fringes is so much increased that it is difficult to fix precisely on the centre of fringes. The light was coloured by the use of five different red glasses (one of which made the light nearly homogeneous) and of one green glass. I am, Gentlemen, your obedient Servant, Observatory, Cambridge, May, 161833. G. B. AIRY.

* See our Numbers for February, March, April and May.-Evrr. 